\title{
A Field Study of the Impact of a Performance-Based Incentive Plan
}

\author{
Rajiv D. Banker* \\ University of Minnesota \\ Seok-Young Lee \\ Sungshin Women's University \\ Gordon Potter \\ Cornell University
}

* Corresponding author

\section{Author Note:}

Rajiv D. Banker, Carlson School of Management, University of Minnesota, Minneapolis, MN 55455; Seok-Young Lee, Department of Management, Sungshin Women's University, Seoul, South Korea; Gordon Potter, School of Hotel Administration, Cornell University, Ithaca, NY 14853.

We are grateful to Carla Ailes, Delores Boehme, Judy Carlson, Robert Girling, Louise Hanne, Birch Holt, Spencer Johnson, Ann Rasmussen, David St. Clair, Joan Starr, and especially Robert Klein and Ertugrul Tuzcu, for providing their time and access to data that made this study possible. Helpful comments and suggestions from Ross Watts (the editor), an anonymous referee, and seminar participants at the 1992 annual meeting of the American Accounting Association. Boston College, Boston University, Carnegie Mellon University, City University of Hong Kong, City University of New York, Cornell University, Dartmouth College, Hong Kong University of Science and Technology, Indiana University, University of Michigan, University of Minnesota, and Vanderbilt University are gratefully acknowledged. Seok-Young Lee acknowledges partial research support from the Sungshin Women's University. 


\begin{abstract}
Much management accounting research focuses on design of incentive compensation contracts. A basic assumption in these contracts is that performance-based incentives improve employee performance. This paper reports on a field test of the multi-period incentive effects of a performance-based compensation plan on the sales of a retail establishment. Analysis of panel data for 15 retail outlets over 66 months indicates a sales increase when the plan is implemented, an effect that persists and increases over time. Sales gains are significantly lower in the peak selling season when more temporary workers are employed.
\end{abstract}

Key words: Incentive compensation; Pay-for-performance; Agency theory; Field study; Retail sales 


\section{Introduction}

Over the past two decades much management accounting research has addressed the optimal design of incentive compensation contracts. Theoretical models are developed based on the assumption that monetary incentives can improve performance by inducing higher levels of effort. Considerable empirical research in accounting and economics has investigated the predictions of these models by examining the structure of executive compensation contracts and their link with firm performance. While this prior research primarily examines the structure of compensation contracts for top executives, our focus is on the impact of a pay-for-performance plan implemented for front-line workers. Specifically, we report on a field test of the multiperiod incentive effects of a performance-based compensation plan implemented by a major retailer for its sales consultants.

Many firms have recently implemented output-based incentive plans that link compensation to measured performance for employees at every level, not just for those at the top (Schlesinger and Heskett, 1991b). Interest in the effect of such incentive plans on worker performance dates back at least to the scientific management studies of Taylor (1911). Much of the related evidence, however, is either anecdotal, or limited to analysis of data for relatively short periods of time without controlling for other factors influencing performance. Some empirical and experimental evidence reported in the organization behavior and related literatures, in fact, cautions against expecting the provision of monetary incentives to translate into improved performance (Pearce, Stevensen, and Perry, 1985; Hogarth et al, 1991). ${ }^{1}$

\footnotetext{
${ }^{1}$ In the organization behavior literature dating back to the 1960s, expectancy theory (Vroom, 1964) and goal-setting theory research (Locke, Bryan, and Kendall, 1968) based on laboratory experiments suggest a link between monetary incentives and performance under controlled situations. However, cognitive constraints limiting the ability of human decision makers to process complex long-term implications of
} 
In contrast to the prior research in these literatures, our study presents a longitudinal examination of the multi-period impact of an incentive plan at several stores operated by a major firm in the department store industry. The stated objective of this plan is to motivate sales personnel to provide enhanced customer service. The plan provides sales personnel with a bonus payment, in addition to their base hourly wage, for exceeding a prespecified sales goal. It also provides for possible termination of employment in case the sales target is not met in two consecutive quarters. Monetary incentives are particularly important in this firm because they comprise about $20 \%$ of base wages, and other reward mechanisms such as promotions are not readily available in a relatively flat organization. Prior to the plan's implementation, salesforce compensation was based primarily on seniority, not performance. Moreover, the firm implemented the plan on different calendar dates at only 15 of the 34 retail outlets it operates over a relatively homogeneous geographic region. This provides us with a natural control group for our study.

Economic theory of incentives predicts that the implementation of a sales- based bonus plan induces greater effort and also attracts more productive workers and, therefore, on average higher levels of sales are realized. Furthermore, the theory predicts that any realized sales gains on implementation persist and even increase as workforce composition changes. Sales gains will increase if customer service is enhanced as expected by firm management because customer satisfaction results in repeat customer purchases in subsequent periods. Finally, because temporary employees cannot trade-off current customer service effort against future multi-period payoffs due to repeat sales to customers, the extent of sales gains is predicted to be lower in peak sales periods when more temporary workers are employed. Our econometric analysis of pooled 
cross-sectional and time-series data for 15 outlets over a 66-month period provides empirical support for these period-specific hypotheses.

The paper is structured as follows. Section 2 describes the research site and the nature of the performance-based contract. Section 3 develops the hypotheses to be tested based on predictions from economic theory of incentives. The model and estimation procedures are described in Section 4. Empirical results are discussed in Section 5 and sensitivity analysis is presented in Section 6. Concluding remarks are offered in Section 7.

\section{Research Site}

\section{Incentive plans in the retail industry}

The past decade has evidenced a concerted effort by many firms to motivate employees to improve performance. Twenty-three percent of the firms in a Coopers and Lybrand (1992) survey indicated that they are implementing new performance-based incentive plans for their employees. In order to deliver quality customer service, many retailers such as Nordstrom, Bloomingdale's, Rich's, Macy’s, Carter Hawley Hale, and the Bon (in Boise, Idaho), have implemented or expanded their incentive pay plans (Ginsberg 1989; Barmash, 1989; Lloyd, 1989). Schlesinger and Heskett (1991a) report that Nordstrom, Younkers, and Dayton Hudson have implemented performance-based compensation plans intended to produce 'extra employee effort' leading to 'extraordinarily responsive service'. An Ernst and Young survey of the retail industry (Bivins, 1989) indicates that most department stores currently offer incentive programs such as straight commissions, base salary plus commission, and quota bonus programs. Although these programs can add to payroll costs, the survey respondents indicated that they believe these plans have contributed to major improvements in customer service. 
Not all retailers, however, are pleased with the performance implications of their outputbased plans. Women's Wear Daily (January 16, 1991) reports that Carter Hawley Hale Stores cut its sales commission dramatically and returned to an hourly wage system in four of its divisions. Sears faced a union-organizing drive and a lawsuit from employees. The Wall Street Journal (Schwadel, January 13, 1990) reports: 'The fuss at Sears... reflects industry-wide skepticism among salespeople about retailers' efforts to shift their compensation to commissions from guaranteed hourly wages'. Moreover, Simons and Weston (1991) cite complaints by Nordstrom employees which suggest that focusing behavior on retail sales can lead to a feeling of intense competition among sales consultants which, in turn, can result in resentment that they are being 'used' by management. ${ }^{2}$

An article in Forbes (Koselka, 1991) notes a $36 \%$ increase in retail square footage and a drop of $16 \%$ in retail sales per square foot in the last decade, and suggests that increasing sales productivity has become a competitive necessity for most retail firms. A New York Times article (Stevenson, August 27, 1989) reports: 'After years of concentrating on keeping costs low and luring customers with constant rounds of sale prices, the large department and apparel stores increasingly see competent service from an efficient, cheerful sales staff as the key to success in an increasingly competitive retailing environment...(Nordstrom's) success has spurred (its) rivals... to initiate strategies like putting salespeople on commission, a step they hope will foster more helpful attitudes in their employees.' A competitive strategy that features customer service led the firm that is the subject of our study to consider using an incentive compensation plan as a means to increase sales at its retail outlets.

\footnotetext{
${ }^{2}$ Baker (1990, p. Dl) writes: ‘...dissent salespeople complain about intense competition between salespeople. Often cited is the court case in King County, Washington, where a jury awarded $\$ 180,000$ to a former Nordstrom saleswoman who claimed that she was wrongfully dismissed because co-workers wrote anonymous letters claiming that she stole from them by falsely crediting herself with their commissions'.
} 


\section{Implementation of incentive plan}

Our research site is a national retail firm that operates a number of department stores selling similar merchandise. While the stores cover a large geographic area, most of the stores are located in or near shopping malls or urban areas. The company initiated its performancebased incentive plan in 1987 to support its stated firm-wide strategy of 'customer emphasis' with 'employee empowerment'. Examination of internal correspondence related to the design of the incentive plan indicated that management expected the plan to result in further enhancement of customer service and consequently in an increase in store sales. Documents distributed to the workers describing the plan also stressed enhanced customer service as its objective.

While we initially selected the firm because of our access to its senior managers, we pursued this research study because it presented a unique opportunity for an experimental design that allowed us to specify and test formal hypotheses about multi-period impacts of the incentive contract. We spent a total of 196 hours at the research site interviewing personnel from human resources, finance, accounting, information systems, and stores departments; meeting with staff working directly with store personnel; visiting retail stores; and collecting relevant data from the company's accounting records.

The plan was implemented in stores sequentially as company managers intended to examine and evaluate the plan's impact on sales and customer satisfaction. Initially, the firm selected one store from a group of similar stores to begin the implementation. By the end of 1988, four stores had implemented the plan and another seven were added in 1989. In 1990, four more stores implemented the plan, bringing the total to 15 out of a total of 34 in this geographic region. Senior managers in finance, human resources, and stores (sales) departments involved in 
the design and implementation of the plan assured us that stores were chosen initially for implementation only because they were representative of others. Detailed examination of internal correspondence did not reveal any other special consideration in their selection. Company managers decided to hold back some stores until they had assessed the plan's impact on salesforce performance. They closely monitored the sales of the first few stores that implemented the new compensation plan by comparing their sales against the sales of a control group of stores. Sequential implementation was also necessitated by the limited number of headquarter staff personnel who were present on site during the initial phases of a store's implementation to explain plan details.

The performance-based incentive plan is best described as a bonus program. At the time of the plan's implementation, sales consultants received little in the form of annual merit increases, and promotions were rare. Bonus payment became the only significant reward for high performance. Each week sales consultants are paid a base hourly rate times hours worked. Under the plan sales consultants can increase their remuneration by receiving a cash bonus at the end of each quarter if the quarterly sales generated by the employee exceed a quarterly sales goal. Failure to meet the goal in two successive quarters may result in termination of employment. Prespecified sales goals are established for each employee based only on the individual's base hourly rate, and department or merchandise group. The bonus is computed as a fixed percentage of the excess sales (actual sales minus prespecified sales goal) by the employee in a quarter. Under the plan, sales department supervisors and managers are also paid a quarterly bonus as a percentage of excess sales. The bonus percentage for these managers is set at one half the bonus rate used for sales consultants. Hence, all operations personnel at the stores who are directly responsible for customer service are covered by the new incentive compensation plan. 
Senior managers regarded the incentive plan as a major change for the firm and its salesforce. They expected that the new incentive scheme would motivate many changes in employee behavior that would enhance customer service. Sales consultants were now expected to build a client base to generate repeat sales. Actions consistent with this approach include developing and updating customer address lists (including details of their needs and preferences), writing thank you notes, contacting customers about upcoming sales and new merchandise that matched their preferences, and retrieving merchandise from other departments. These changes in the activities of the salesforce necessitated changes in the role of sales managers. After the plan's implementation, the managers became responsible for supporting the consultants' customer service activities and their role became more of a facilitator as sales personnel gained more autonomy. The plan's implementation also required managers to deal with the administrative problems that result from the plan, such as consultants' demands for prime selling hours, disputes over credit for sales, and instruction to employees who had sub-par selling performance.

To aid the transition, plan implementation was preceded by a number of question and answer sessions and store visits by corporate staff. Prior to actually beginning the plan a party was staged for all store personnel. Corporate staff remained on site for a few months to help store management with the implementation. Because of the many changes, management expected that any sales increases might occur gradually as employees learned how to provide a higher level of service to customers and developed their client base. Personnel managers indicated to us that in November and December temporary employees are used extensively. Company documents examined by us confirmed that compared to the other ten months, the increase in total hours employed in both plan and nonplan stores is almost $20 \%$ in November and December. Company officials were concerned that most temporary employees would have limited opportunity to use 
these new selling strategies emphasizing customer service. Therefore, although they expected sales to increase upon implementation of the plan, and detailed contingent analyses had been prepared, they recognized that assessing the magnitude and persistence of sales gains given the many complexities of the plan and its environment was difficult.

\section{Development of Hypotheses}

Agency theory is one paradigm that suggests a value for performance-based compensation. Examples of agency-theoretic models for examining salesforce compensation include Basu, Lai, Srinivasan, and Staelin (1985), Lai and Staelin (1986), and Rao (1990). John and Weitz (1989) and Coughlan and Narasimhan (1992) use questionnaire surveys to examine factors influencing salesforce compensation structure. Empirical research on executive compensation contracts also draws on agency theory to evaluate the link between compensation and alternative measures of performance (e.g., Jensen and Zimmerman, 1985; Murphy, 1985; Coughlan and Schmidt, 1985; Benston, 1985; Gibbs, 1995; Holthausen, Larcker, and Sloan, 1995). For instance, studies such as Lambert and Larcker (1987) and Sloan (1992) provide limited evidence in support of Banker and Datar's (1989) result that the weights placed on different performance signals, such as stock returns and accounting returns, are proportional to the sensitivity and precision of the signals. Antle and Smith (1986) and Jensen and Murphy (1990) find little empirical support for Holmström's (1982) theoretical result that top executive contracts are optimally based on relative performance measures. However, Gibbons and Murphy (1990) find limited evidence that executive compensation is related to industry-adjusted rates of 
return. In an important article, Baker, Jensen, and Murphy (1988) synthesize the research in this field and reconcile empirical evidence with economic analysis of incentive contracts.

In the basic agency model, a principal designs a contract to motivate a risk- and effortaverse agent to exert unobservable effort in a production process that is characterized by uncertainty. Two optimization assumptions are maintained in this model. First, the principal is assumed to optimally choose a contract based on observable performance signals. Next, given the compensation contract, the agent is assumed to optimally trade-off disutility for higher effort against expected utility for higher incentive compensation resulting from improved performance. At our field research site, the intent of the management was to test and fine-tune the incentive plan that was implemented for front-line workers. Consequently, we do not expect that this performance-based incentive plan is optimal under the realized conditions nor do we test for its optimality. ${ }^{3}$ Our objective instead is to examine whether the performance of the agents changed on the implementation of the new incentive plan as if they were optimizing their effort choices given the contract.

\section{Plan effect}

Sales personnel in the retail industry expend considerable effort to provide customer service and to promote and obtain sales. At our research site, straight salary had been used for the salesforce prior to incentive plan implementation. To the extent these flat salary levels were above the workers' going rate, efficiency wage theory suggests that employees had the incentive

\footnotetext{
${ }^{3}$ Jensen and Murphy (1990, p. 246) note: 'the structure of the Holmström model makes its conclusions irrelevant to most compensation contracts ... His model assumes that the principal knows the utility function of the (agents) as well as the production function relating actions to expected outcomes... (T)his means that (the principal) knows with certainty all possible actions of the (agents)... the distribution of outcomes of each action... (and) the set of optimal... actions. It is unlikely that these conditions are often satisfied'.
} 
to exert higher than the minimal effort in order to maintain their current employment. Further, to the extent that sales supervisors and managers provided (imperfect) monitoring of sales consultants' effort, consultants were motivated to direct their effort in the desired direction. However, supervisory monitoring continued after the implementation of the new incentive plan, and the base salary under the new plan was maintained at the old level. Therefore, agency theory predicts that the implementation of this new performance-based incentive contract will induce the sales consultants and managers to exert greater effort to generate more sales. ${ }^{4}$

Performance-based incentives also have the effect of revealing the intrinsic productivity of sales consultants unknown to the firm (Murphy, 1986). If the more productive workers have the better outside opportunities, implementation of a pay-for-performance system 'amounts to offering a menu because it allows employees to determine their compensation by how hard they choose to work. Indeed, paying a wage that is based on measured performance tends to attract and retain the most productive job applicants and to discourage the least productive, to the employer's benefit' (Milgrom and Roberts 1992, p. 157). As a result, with more productive sales consultants, we expect sales to increase on the implementation of the new performance-based incentive plan. To test this basic prediction, we specify the following hypothesis:

\footnotetext{
${ }^{4}$ The ability of the incentive plan to motivate increased effort by employees may be attenuated by potential ratcheting effects. The ratcheting effect is a multi-period incentive problem which arises from the tendency of firms to use the most current performance as a criterion in determining the next period's goal (Weitzman, 1980; Homans. 1952). For instance, Clawson (1980) finds that because employers always adjusted the rate they paid to piecework employees downward, piecework incentives rarely worked in the early 1900's as workers quickly learned to restrict output. Discussions with senior managers at our research site, however, indicated that performance goals under the plan were based on industry standards and therefore they did not intend to make any adjustments. Examination of company records also confirmed that no changes occurred during the period of our study. Therefore, we do not expect that dysfunctional behavior was induced by the ratcheting phenomenon.
} 


\section{$H_{1}$ : Ceteris paribus, sales increase following the implementation of the performance- based compensation plan.}

While the economic arguments supporting this hypothesis are intuitive, prior work in the organization theory literature presents contrary evidence. Pearce, Stevensen, and Perry (1985) report no discernable effect on performance when a new incentive compensation plan based on performance measures such as claim turnaround time was implemented for social security administrators. Reviewing experimental research, Hogarth et al. (1991, p. 735) state: 'It would be naive to assert that incentives always improve performance'. They cite Deci and Ryan (1985), Lepper, Greene, and Nisbett (1973), and Levine and Fasnacht (1974) who report that in performing a task that subjects find intrinsically interesting, introduction of monetary incentives decreases subsequent interest and performance because incentives are 'experienced as controlling and they frequently convey a sense of incompetence'.

Behavioral research in accounting also questions the ability of monetary incentives to improve performance. Awasthi and Pratt (1990) report that provision of monetary incentives does not result in improved performance for subjects with low intuitive and perceptual abilities to perform a complex task. Ashton (1990) appeals to prior research in psychology (Condry, 1977; Guzzo, Jette, and Katzell, 1985; Jenkins, 1986; McGraw, 1978; Thaler, 1986) that suggests that while financial incentives improve performance if the task is 'boring or monotonous' or if 'solutions involve straightforward, perhaps mechanical solution procedures

\footnotetext{
${ }^{5}$ Similar arguments are also presented in popular magazines. For instance, Kohn (1988) states that monetary rewards 'encourage people to focus narrowly on a task, to do it as quickly as possible, and to take few risks ... Extrinsic rewards can erode intrinsic interest ... (and), people come to see themselves a being controlled by a reward'. See also Baker, Jensen, and Murphy (1988) for a review of this literature. They note in particular that it is not that monetary incentives do not work, rather they work too well in focusing attention to measured outcomes linked with incentives to the exclusion of other desired outcomes.
} 
that clearly exist', such incentives are detrimental if the task is 'interesting for its own sake' and if it involves 'neither a clear solution procedure nor an obvious way to create or discover one'. Ashton finds that monetary incentives increase performance pressure on a subject, and the increased pressure harms performance when the task is demanding and has a high level of preexisting pressure. ${ }^{6}$ Because enhanced customer service requires more creative application of effort by sales consultants in a high pressure setting where poor performance may result in termination of employment, the above studies suggest that the introduction of monetary incentives may have a detrimental effect on performance. Our study, therefore, serves as a test of the external validity of these experiments.

\section{Year effect}

The conventional wisdom in the retail industry is that monetary incentives linking pay to performance motivate sales consultants to provide better customer service (Schwadel, 1990). Discussions with company personnel and examination of company documents revealed that a similar expectation about enhancement in customer service existed at our research site when the new pay-for-performance plan was implemented. The agency-theoretic notion of 'higher effort' translates in the retail industry into sales consultants developing and maintaining greater information about the wants of the customers, and working to satisfy those wants, thus leading to a higher level of customer satisfaction. While these actions drive current-period sales, they will increase future sales as well, as sales personnel build their own client bases and satisfied customers generate repeat purchases. The cumulative benefits from a sustained higher level of

\footnotetext{
${ }^{6}$ In contrast to these papers, Libby and Lipe (1992) document in their experimental study that performance-based incentives increase effort, and consequently improve performance, when the outcome is sensitive to the effort level.
} 
effort under the incentive plan imply, therefore, that the sales gains in subsequent periods will be greater than the gains obtained immediately on implementation.

A concern about this prediction stems from the possible multidimensionality of agents' effort. If the sales consultants direct more effort to enhance customer service, as company management expects, then both current and future sales will increase. However, sales consultants may direct their effort to increase current sales without enhancing customer service. For instance, a Wall Street Journal article (Yin, 1992) reports the California Department of Consumer Affairs' finding that Sears, Roebuck \& Co. overcharged auto-repair customers nearly $90 \%$ of the time, by an average of $\$ 223$, for additional and more expensive repairs than were needed. The department believed that the overcharges resulted because of pressure on repairmen to meet quotas of parts and service repair sales for every eight-hour shift.

Such behavior is predicted by Holmström and Milgrom's (1991) two-dimensional effort model where the outcome (e.g., customer service) of one of the effort dimensions cannot be measured at all. If monetary incentives are based on the outcome (e.g., current sales) of the other effort dimension, then dysfunctional behavior ensues with excessive effort being directed to the effort dimension being rewarded by performance-based incentives. However, in a multi-period situation such as the one we encounter at our research site, sales in future periods serves as a comparable, though less precise, measure of the customer service effort dimension. Therefore, agents will consider the two measures (current sales and future sales) on which their monetary incentives are based, and both the precision and the sensitivity of the two measures will influence the impact of incentives on effort (Banker and Datar, 1989; Feltham and Xie, 1994). To the extent that the customer at a department store is as well informed about his/her wants as the salesperson (unlike the auto-repair case mentioned earlier), the ability of a salesperson to 
increase current sales without providing better customer service is limited. Therefore, the sensitivity of the measure (future sales) for customer service effort dimension is higher, even though its precision is lower than that of the short-horizon (current sales) effort dimension. As a result, for salespersons with a longer multi-period decision horizon, provision of incentives based on sales performance is likely to enhance effort along both dimensions, rather than only one to the exclusion of the other as in the Holmström-Milgrom model.

Sales gains are also expected to increase over time if provision of incentives motivates employees to learn improved ways of performing their tasks over time. Economic theory suggests that workers with a longer multi-period decision horizon will devote some of their effort to learn more productive ways to perform their tasks if they are provided incentives based on improved performance. Latham and Dossett (1978), for instance, found that incentive wages led to animal trappers learning new ways to identify 'active' animal lairs. Learning effects occur as workers become more familiar with their new responsibilities, adopting more productive procedures and eliminating unproductive activities (Wagner, Rubin, and Callahan, 1988). ${ }^{7}$

Sales gains may also increase over time as less effective employees, unhappy with the new performance evaluation program, leave and are replaced by personnel with higher intrinsic ability, who prefer output-based compensation plans (Rao, 1990). As noted earlier, economic theory suggests that in such adverse selection situations involving a pool of workers with different levels of intrinsic ability, a contract that is contingent on performance will induce a separating equilibrium with the higher-ability workers optimally accepting the contingent contract and the lower-ability workers rejecting it. In effect, we expect that over time the firm

\footnotetext{
${ }^{7}$ However, recent behavioral studies (Kanfer and Ackerman, 1989; Wood, Bandura, and Bailey, 1990) suggest that the presence of monetary incentives diverts needed attention from 'a concern about how to $d o^{\prime}$ a complex task to ' $h o w$ well one is doing', thus inhibiting learning of that task. Such a shorter-term focus on current output implies that sales gains will not increase over time if sales personnel do not invest their effort in learning the complex tasks in retail selling.
} 
will attract more high-ability workers and retain such workers already in its employment, but lose the lower-ability workers in its employment at the time the new incentive contract was implemented.

That sales gains will increase over time is predicted by all three explanations: the effect of increased customer satisfaction, the effect of consultants learning improved methods, and the adverse selection effect of attracting more productive workers. With our data limited only to store sales during our sample period, we cannot discriminate between these competing explanations. Instead, we limit ourselves to the more modest task of testing the following hypothesis:

\section{$\mathrm{H}_{2}$ : Ceteris paribus, sales gains realized on the implementation of the performance-based incentive plan persist and increase over time.}

In contrast, sales increases realized during the initial stages of the new plan may be explained by the fact that the sales personnel are being given special attention and are enjoying the novel experience. To the extent such a placebo or so-called Hawthorne Effect (Roethlisberger, 1977) is driving performance, sales gains are expected to diminish or even disappear over time (Schlesinger and Heskett, 1991a). While the Hawthorne experiments are popularly associated with the effect of temporary productivity gains arising only because of increased attention during the experiment, careful statistical analysis of the Hawthorne data has revealed a persistent gain due to a learning effect in the presence of increased monetary incentives and performance feedback (Parsons, 1974; Pitcher, 1981). An alternative reason to expect only transient gains is that they arise because of increased monitoring associated with the 
presence of corporate staff during the implementation phase of the plan. Performance gains attributable to this increased monitoring diminish as the involvement of corporate staff at the plan site and in carefully watching and comparing store sales is reduced.

\section{Seasonal effect}

The seasonal nature of the retail business requires firms to hire temporary employees during busy seasons. This fact motivates a further hypothesis derived from the multi-period nature of the impact of higher effort. A permanent sales consultant will take into account the present value of expected future bonuses, and weigh it against the disutility for higher effort. In contrast, a temporary employee has only a short-term focus. This difference in incentives implies that a permanent sales consultant will work more to build a client base than a temporary salesperson. ${ }^{8}$ If improved customer service is the predominant means for increasing sales, then the lower effort by temporary workers implies lower sales, on average. In a similar vein, because temporary workers have less incentive to devote effort to learn the retail selling task, they will exhibit lower sales gains. Also, temporary workers may not be as skilled as permanent workers in providing superior customer service and, as a result, the introduction of the incentive plan may not result in as high an improvement in performance. We hypothesize, therefore, that the higher the proportion of temporary salespeople on the sales floor, the lower the impact of the performance-based program on sales. Because retailers hire considerably more temporary parttime employees for fourth-quarter (holiday season) business, we expect the sales impact of performance-based incentives to be smaller in the fourth quarter than in the other three quarters.

\footnotetext{
${ }^{8}$ Schlesinger and Heskett (1991b) report that Sears found from its 1989 customer survey that 'the more a store relied on a continually changing group of part-timers...the lower the customer ratings it received. The higher its percentage of full-time and regular part-time workers, the more satisfied customers said they felt'.
} 
Furthermore, many more transient rather than repeat customers shop in the holiday season.

Because it is more difficult to provide high levels of service to nonregular customers, the incentive effects of the plan are reduced during the holiday season. Therefore, we test the following hypothesis:

\section{$\mathrm{H}_{3}$ : Ceteris paribus, the impact of the performance-based contract on sales in the}

fourth quarter is less than its impact in the other three quarters.

In contrast, if temporary workers can take actions that promote current sales, sacrificing future sales as in the Holmström-Milgrom (1991) model, they will have the incentive under the new compensation contract to do so; and as a result sales would increase in the period when more temporary workers are used. For instance, a temporary sales consultant will have incentives not to tell the customer to wait and buy the item later after it goes on sale. ${ }^{9}$

\section{Model Specification}

Empirical testing of the hypotheses derived in the previous section involves assessing the impact of the incentive plan on store sales. We obtained monthly store sales reports for a 66month period (from February 1986 to July 1991) for the 15 stores that implemented the incentive plan and the 19 other stores in the same geographic region that did not. To estimate the plan's

\footnotetext{
${ }^{9}$ Empirical evidence from prior research in the retailing literature suggests that part-time labor has a positive influence on sales productivity, and this influence is stronger for stores that emphasize customer service rather than stores that are primarily self-service (Thurik and Van der Wijst, 1984). One reason for this effect is that temporary employees seek full-time jobs within the organization, and expect to improve their prospects by exhibiting superior performance. Provision of monetary incentives therefore may not appreciably enhance this existing incentive.
} 
effect we specify the following model of sales in month $t, t=1, \ldots, 66$, of each store $s, s=$ $1, \ldots, 15$, that implemented the plan:

$$
\begin{gathered}
S A L E S_{s t}=\sum_{s=1}^{15}\left(\alpha_{s} D_{s}+\beta_{s} D_{s} A V G \operatorname{COSA} L_{t}\right)+\lambda_{1} D_{s t}^{P} S A L E S 86_{s} \\
+\lambda_{2} D_{s t}^{P} D_{s t}^{Y} S A L E S 86_{s}+\lambda_{3} D_{s t}^{P} D_{s t}^{Q} S A L E S 86_{s} \\
+\lambda_{4} D_{s t}^{P} A V G \operatorname{COSAL} L_{t}+\lambda_{5} D_{s t}^{P} D_{s t}^{Y} A V G \operatorname{COSA} L_{t} \\
+\lambda_{6} D_{s t}^{P} D_{s t}^{Q} A V G \operatorname{COSAL} L_{t}+\varepsilon_{s t}
\end{gathered}
$$

where

SALES $\quad=$ sales of store $s$ in month $t$,

$A V G C O S A L_{t}$

SALES86

$D_{S}$

$D_{s t}^{P}$

$D_{S t}^{Y}$

$D_{s t}^{Q}$
$=$ average sales in month $t$ of 19 'control' stores that did not implement the incentive plan, $=$ average monthly sales of store $s$ in fiscal year February 1986 to January 1987, $=1$ if store $s$, otherwise zero, $=1$ if store is on the incentive plan, otherwise zero, $=1$ if store has been on the incentive plan for at least one year, otherwise zero, $=1$ if fourth quarter of fiscal year, otherwise zero.

In this formulation store sales are specified as an intercept as plus a multiple $\left(\beta_{s}\right)$ of $A V G \operatorname{COSAL} L_{t}$. The $\beta$ parameters vary across stores principally due to relative store size; stores larger than the average 'control' store have $\beta$ 's greater than one, smaller stores less than one. We compute the $A V G \operatorname{COSA} L_{t}$ measure for each month $\mathrm{f}$ using the 19 stores that did not implement the plan and thus control for changes in sales over time because of the potentially unique selling strategies of the firm as well as seasonal and regional economy-wide effects. We estimate the model's parameters using pooled time-series data over a 66-month period and cross-sectionally for the 15 stores that implemented the incentive plan. 
Observe that we multiply each intercept shift term (the three terms with coefficients $\lambda_{1}$, $\lambda_{2}$, and $\lambda_{3}$ ) by $S A L E S 86_{s}$, the average monthly sales for stores in fiscal year February 1986 to January 1987, the first year in our sample. If we had not multiplied by $S A L E S 86_{s}$, then the model would have implicitly restricted the impact of the plan to be equal across all 15 stores. But, intuitively, we expect sales gains to be higher for larger stores and lower for smaller stores. We examined this issue by estimating the model in (1) without multiplying the three terms by $S A L E S 86_{s}$, and correlating its residuals for months subsequent to the plan's implementation with SALES86 for each store. This correlation is significantly positive $(\mathrm{p}=0.002)$ indicating that the plan impact varies directly with store size, and model (1) estimates will be potentially biased if we do not multiply the three intercept shift terms by SALES86 for each store.

We test for the hypothesized effects of the incentive plan on sales by examining the intercept shift coefficients, $\lambda_{1}, \lambda_{2}, \lambda_{3}$, and slope shift coefficients, $\lambda_{4}, \lambda_{5}, \lambda_{6}$, in model (1). A positive $\lambda$ is interpreted as the incentive plan having a positive effect on sales. We estimate three versions of the model in (1), first with only slope shifts (setting $\lambda_{1}=\lambda_{2}=\lambda_{3}=0$ ), second with only intercept shifts (setting $\lambda_{4}=\lambda_{5}=\lambda_{6}=0$ ), and third with both slope and intercept shifts. The slope- shift model assumes that the impact of incentive plans is proportional to the $A V G C O S A L$ measure that varies considerably over time due to seasonal and economic factors, but is invariant across stores. The intercept-shift model assumes that plan impact is invariant over time except for the second-year and fourth-quarter effects modeled explicitly in (1). By estimating the three different versions of model (1), we seek to demonstrate the robustness of our results.

The first hypothesis, $H_{1}$, states that sales increase on the implementation of the incentive plan. We test this hypothesis by examining whether the $\lambda_{1}\left(\right.$ or $\left.\lambda_{4}\right)$ coefficient is greater than zero. 
The second hypothesis, $\mathrm{H}_{2}$, states that sales gains increase over time, and is evaluated by examining whether $\lambda_{2}$ (or $\lambda_{5}$ ) is greater than zero. If the change in performance during plan implementation is only due to the Hawthorne Effect, then a decrease in plan impact over time is expected, as reflected in $\lambda_{2}$ (or $\lambda_{5}$ ) being less than zero. Finally, the third hypothesis, $H_{3}$, states that sales gains are negatively related to the presence of temporary employees. Therefore, we test whether the average impact of the plan on fourth-quarter sales, when temporary employment is high, is less than that of the other three quarters, as reflected in $\lambda_{3}\left(\right.$ or $\left.\lambda_{6}\right)$ being less than zero.

Because we use time-series information to estimate the effect of the incentive plan on sales, serial correlation may bias the standard errors of the coefficients. We control for autocorrelation by using a variant of the Prais-Winsten (1954) estimator proposed by Park and Mitchell (1980) to make first-order autocorrelation adjustments to the variables. This estimator is consistent and performs especially well for short time series and trended data relative to several other estimators (Doran and Griffiths, 1983). It also reduces the extent to which the autocorrelation coefficient tends to be underestimated (Kmenta and Gilbert, 1970). We test the hypotheses using the parameter estimates from the regression using the transformed variables.

We also expect to find heteroscedasticity, as the observations for larger stores are likely to have bigger variances. The initial OLS results using the Glesjer (1969) test confirm this suspicion as the absolute error terms are significantly correlated (Pearson correlation $=0.501$, Spearman correlation $=0.376, p=0.0001$ ) with the square root of store size measured in square feet. Therefore, we conduct weighted-least-squares (WLS) estimation under the assumption that error term variances are proportional to square feet of store space. We also conduct tests using White's (1980) procedure to obtain consistent estimates of the standard errors from an OLS 
regression. Standard errors and coefficients were higher using White's procedure, but test results were similar.

\section{Empirical Results}

Table 1 presents average statistics on store sales and square footage by existence of the incentive plan as of the end of our sample period. Because of the sensitivity of the information, the data have been disguised by multiplying by a scalar. The median square feet for the incentive plan and nonplan stores are identical, and the difference in the means is not statistically significant. There are also no statistically significant differences in store size measured in sales for fiscal year 1987-88, the year incentive-plan implementation began. This finding is consistent with management's intent to initially select representative stores for implementation to help assess the impact of the performance-based compensation plan. As expected, the average sales for the plan stores have grown more than those for the nonplan stores by fiscal year 1990-91, the last complete year in our sample, but the difference is not statistically significant. Table 2 presents a comparison of three key financial ratios for the plan and nonplan stores. There are no statistically significant differences in inventory/sales, and cost of sales/sales ratios for 1987-88 or 1990-91. The support expenses/sales ratio is greater on average for the nonplan stores, the difference is statistically significant for 1990-91.

Insert Table 1 Here

Insert Table 2 Here 
Fig. 1 presents a plot of the average standardized sales residuals for the 15 plan stores. The residuals are aligned in event time with month 0 representing the date of the plan's implementation. The residuals for each plan store are computed as prediction errors from the following model: ${ }^{10}$

$$
S A L E S_{s t}=\alpha_{s}+\beta_{s} A V G \operatorname{COSAL} L_{t}+e_{s t}
$$

where $\alpha_{s}$ and $\beta_{s}$ are stimated using data for up to 24 months prior to the implementation date. The graph reveals a steep increase in sales in the month of the plan's implementation, and that the sales gains persist and increase over the 24-month period following the implementation date. Statistical tests of the nature of performance change follow.

Insert Table 3 Here

Insert Figure 1 Here

To assess the effect of the incentive plan on store sales, we present in Table 3 the results of WLS estimation of the regression model with Park-Mitchell transformations of the variables. Because there are numerous stores, we report only the coefficients relating to the incentive plan. The regression on the left (column 1) reports results of estimating the following model, restricting the intercept shifts in model (1) to be zero:

\footnotetext{
${ }^{10}$ Residuals are standardized by dividing by the square-root of estimated variances, where the out-ofsample prediction error variances include an adjustment for increasing variance (Johnston, 1984, p. 43). The apparent increase in monthly variability after the implementation date is explained by the fact that the number of observations decreases over time because of the sequential implementation of the plan.
} 


$$
\begin{gathered}
S A L E S_{s t}=\sum_{s=1}^{15}\left(\alpha_{s} D_{s}+\beta_{s} D_{s} A V G \operatorname{COS} A L_{t}\right)+\lambda_{4} D_{s t}^{P} A V G \operatorname{COS} A L_{t} \\
+\lambda_{5} D_{s t}^{P} D_{s t}^{Y} A V G \operatorname{COS} A L_{t}+\lambda_{6} D_{s t}^{P} D_{s t}^{Q} A V G \operatorname{COSAL} L_{t}+\varepsilon_{s t}
\end{gathered}
$$

Individual store coefficients $\beta_{s}$ ranged between 0.503 and 2.265 , and averaged 1.140 . The estimated $\lambda_{4}$ coefficient is 0.105 with a $t$-statistic of 8.94 , indicating that the incentive plan had a statistically significant positive effect on sales, thus supporting our first hypothesis. The estimated $\lambda_{5}$ coefficient $(0.051, t$-statistic 3.73$)$ reveals that the impact of the incentive plan increases significantly over time, supporting our second hypothesis. There is no indication that the impact of the plan has diminished over time and, therefore, the presence of the Hawthorne Effect as the primary driver of sales gains during the early stages of implementation is not directly supported by the data. It is possible, however, that the increase over time due to the multi-period effect of incentives is being partially offset by an initial period Hawthorne Effect. The estimated $\lambda_{6}$ coefficient is -0.056 with a $t$-value of -4.72 . This supports our third hypothesis that the sales impact of the plan is lower in the fourth quarter due to the higher proportion of temporary employees in this quarter.

The estimated $\lambda$ coefficients can be used to assess percentage increase in sales after the implementation of the incentive plan. The estimated average sales for a plan store $s$ increase from $\beta_{s}$ times $A V G C O S A L$ to $\left(\beta_{s}+\lambda_{4}\right)$ times $A V G C O S A L$ in the first year (except fiscal quarter 4) after implementation, and to $\left(\beta_{s}+\lambda_{4}+\lambda_{5}\right)$ times $A V G C O S A L$ in the second year. Because the average $\beta_{s}$ is 1.14 across all 15 stores, the average percentage increase is approximately $100 \lambda_{4} /$ 1.14. The results in Table 3 imply that the average increase is about $9.2 \%(=0.105 / 1.14)$ in the first year after plan implementation and 13.7\% $(=(0.105+0.051) / 1.14)$ in the second year. 
We present the results of estimating the intercept-shift-only version of model (1) in column 2 of Table 3. In this case, we estimate the following equation assuming error variances proportional to store size (WLS):

$$
\begin{gathered}
S A L E S_{s t}=\sum_{s=1}^{15}\left(\alpha_{s} D_{s}+\beta_{s} D_{s} A V G C O S A L_{t}\right)+\lambda_{1} D_{s t}^{P} S A L E S 86_{s} \\
+\lambda_{2} D_{s t}^{P} D_{s t}^{Y} S A L E S 86_{s}+\lambda_{3} D_{s t}^{P} D_{s t}^{Q} S A L E S 86_{s}+\varepsilon_{s t}
\end{gathered}
$$

The estimated $\lambda$ coefficients confirm the results from the slope-shift model in column 1 . There is an increase in sales on plan implementation averaging $10.2 \%$ of $1986-87$ sales levels. Sales gains increase by an additional $2.3 \%$ (of 1986-87 sales) in the second year and the gains are lower by about $2.6 \%$ (of $1986-87$ sales) in the fourth quarter.

The specification in column 3 of Table 3 permits both slope and intercept shifts as described in the full model (1). The significantly positive $\lambda_{1}, \lambda_{4}$, and $\lambda_{5}$, and the significantly negative $\lambda_{6}$ support our three hypotheses. The three $F$-tests in the last panel of the table also indicate that each of the three hypotheses $\left(H_{1}: \lambda_{1}=\lambda_{4}=0, H_{2}: \lambda_{2}=\lambda_{5}=0\right.$, and $H_{3}: \lambda_{3}=\lambda_{6}=$ 0 ) is rejected at the $1 \%$ level.

To further evaluate the robustness of our results, we reestimated the slope- shift and the intercept-shift models allowing for store-specific values of $\lambda$. By letting the $\lambda$ coefficients vary across stores, we allowed for the possibility that the plan impact is different for different stores without constraining this differential impact to be proportional to store sales in 1986-87. Results of tests evaluating whether the average estimated value of each $\lambda$ over the 15 stores is zero are very similar to those reported in Table 3. 


\section{Sensitivity Analysis}

While our earlier models attribute the increase in sales to the implementation of the performance-based incentive plan, other factors may explain this result. We investigate three potential alternative explanations: model specification, personal income growth differentials, and sales-related expenses.

Theoretical research in agency theory does not provide an exact functional form to link store sales with agent effort and incentive plan implementation. Therefore, we evaluate the robustness of our results by considering alternative model specifications. Monthly sales of all plan and nonplan stores move together over time because of regional economic factors, seasonality in sales patterns, number of weekends and work days in a month, and company-wide advertising and promotions such as for special anniversary sales. Bivariate correlations between individual store sales for the 15 sample stores and $A V G C O S A L$ over our sample period are high, ranging between $93 \%$ and $97 \%$, thus indicating that the primary drivers of store sales are captured by companywide factors. Therefore, we specify the ratio of store sales to $A V G C O S A L$ as a function of hypothesized incentive plan effects as follows:

$$
\frac{S A L E S_{s t}}{A V G \operatorname{COSAL} L_{t}}=\sum_{s=1}^{15} \beta_{s} D_{s}+\lambda_{1} D_{s t}^{P}+\lambda_{2} D_{s t}^{P} D_{s t}^{Y}+\lambda_{3} D_{s t}^{P} D_{s t}^{Q}+\varepsilon_{s t}
$$

The results in Table 4 reveal that a statistically significant $9.3 \%$ increase in relative sales gain occurred on plan implementation that increased further by $5.0 \%$ in the second year. The estimated lower relative sales gain of $1.6 \%$ in the fourth quarter is not significant. 
Insert Table 4 Here

We also consider the possibility that management selected the stores located in high growth areas for the initial implementation of the incentive plan so that the measured increase in sales for plan stores would exceed that for nonplan stores and, therefore, the implementation of the new plan would appear successful. Table 5 reports average statistics for the annual growth rates in total personal income for the county in which each store is located, classified by the existence of the incentive plan. Over the period from 1984 to 1987, growth in personal income was greater for the counties in which plan stores are located than for the counties in which nonplan stores are located, but the difference is not statistically significant at conventional levels. However, from 1988 to 1990, the average growth rate in county personal income for the plan stores is significantly greater than that for the nonplan stores. Because more disposable income is believed to translate into more sales, the post-implementation sales gains identified in Tables 3 and 4 may be driven by differential personal income growth rates. To examine the impact of income growth on relative sales we reestimate (3) after including relative income growth terms as follows:

$$
\begin{aligned}
\frac{S A L E S_{s t}}{A V G C O S A L_{t}}= & \sum_{s=1}^{15} \beta_{s} D_{s}+y R G I N C_{s t}+\lambda_{1} D_{s t}^{P}+\lambda_{2} D_{s t}^{P} D_{s t}^{Y} \\
+\lambda_{3} D_{s t}^{P} D_{s t}^{Q} & +\lambda_{4} D_{s t}^{P} R G I N C_{s t}+\lambda_{5} D_{s t}^{P} D_{s t}^{Y} R G I N C_{s t} \\
& +\lambda_{6} D_{s t}^{P} D_{s t}^{Y} R G I N C_{s t}+\varepsilon_{s t}
\end{aligned}
$$

Insert Table 5 Here 
The additional variable, $R G I N C$, measures the annual growth rate in county personal income for a plan store relative to the annual personal income growth rate for the 19 regional stores that did not. ${ }^{11}$ This model is based on the assumption that a $\Delta$ increase in relative income growth results in a $y \Delta$ increase in relative stores sales, and that this impact increases to a $\left(y+\lambda_{4}\right) \Delta$ increase after plan implementation.

Similar to the model in (1), we estimate slope-shift $\left(\lambda_{1}=\lambda_{2}=\lambda_{3}=0\right)$, intercept-shift $\left(\lambda_{4}=\lambda_{5}=\lambda_{6}=0\right)$, and both-slope-and-intercept-shifts versions of the model in (4). Two results are evident from Table 6. First, RGINC significantly explains relative store sales. The $y$ values of 0.957 and 0.963 in columns 1 and 2 are not significantly different from 1, indicating that relative store sales increase almost proportionately with relative income growth. That is, a $5 \%$ increase in relative income growth results in a nearly $5 \%$ increase in relative store sales. Second, after controlling for relative income growth, the results in all three columns provide strong support for the first two hypotheses. The signs of all estimated $\lambda$ coefficients in the first two columns are in the hypothesized direction, but $\lambda_{3}$ and $\lambda_{6}$ are not significant. ${ }^{12}$

Table 7 presents results of estimating the model obtained by multiplying both sides of (4) by $A V G C O S A L$. This provides a model similar to model (1) estimated in Table 3. The regression in column 2 is identical to that in column 1 of Table 3 except for the addition of the relative growth term with the $y$ coefficient. The estimated $\lambda$ coefficients in this column of Table 7 are similar to, though slightly lower than, those obtained in the earlier regression suggesting that

\footnotetext{
${ }^{11}$ Specifically, if $I_{s y}$ and $I_{R y}$ denote the personal incomes in a year y for the county of a store $s$ and the entire region $R$ respectively, then $R G I N C_{s t}=\left(I_{s y} / I_{s, 1987}\right) / I_{R y} / I_{R, 1987}$ where $y$ is the year corresponding to the month $t$ and where $I_{s, 1987}$ and $I_{R, 1987}$ denote the personal incomes in the year 1987. ${ }^{12}$ Individual coefficients in column 3 should be interpreted cautiously as Belsley-Kuh-Welsch diagnostics indicate high collinearity. The highest condition index is 90 for the regression in column 3 , well above the highest condition index of 15 for column 3 in Table 3.
} 
growth, while important, does not explain all of the increase in sales that coincides with the plan's implementation. Overall, the results in the table support all three of our hypotheses. ${ }^{13}$

An alternative approach to modeling the impact of $R G I N C$ on store sales is to assume that the coefficient $\beta_{S}$ in model (1) representing the sales of a store $s$ as a multiple of $A V G C O S A L$ is not invariant over time, and the time-dependent $\beta_{\text {st }}$ increase for stores located in counties that exhibit a high personal income growth rate and decrease for other stores. To address the nonstationarity of $\beta_{s t}$, we write $\beta_{s t}=\phi_{s} R G I N_{s t}$ where $\phi_{s}$ are stationary parameters to be estimated. We estimate the following model:

$$
\begin{gathered}
\text { SALES } S_{s t}=\sum_{s=1}^{15}\left(\alpha_{s} D_{s}+\phi_{s} D_{s} A V G \operatorname{COSAL} L_{t} R G I N C_{s t}\right) \\
+\lambda_{1} D_{s t}^{P} S A L E S 86_{s t}+\lambda_{2} D_{s t}^{P} D_{s t}^{Y} S A L E S 86_{s} \\
+\lambda_{3} D_{s t}^{P} D_{s t}^{Q} S A L E S 86_{s}+\lambda_{4} D_{s t}^{P} A V G \operatorname{COSA} L_{t} R G I N C_{s t} \\
+\lambda_{5} D_{s t}^{P} D_{s t}^{Y} A V G \operatorname{COSAL} L_{t} R G I N C_{s t} \\
+\lambda_{6} D_{s t}^{P} D_{s t}^{Q} A V G \operatorname{COSAL} L_{t} R G I N C_{s t}+\varepsilon_{s t}
\end{gathered}
$$

Insert Table 6 Here

Insert Table 7 Here

Parameter estimates reported in Table 8 indicate that while all the $\lambda$ coefficients in the first two columns have the hypothesized signs, the extent of the plan impact is diminished compared to that indicated in Table 3 and hypothesis $\mathrm{H}_{2}$ is not rejected because we now control for income

\footnotetext{
${ }^{13}$ The individual coefficients in column 3 of Table 7 should also be interpreted cautiously as the highest Belsley-Kuh-Welsch condition index is $\mathbf{1 5 6 .}$
} 
growth differentials. However, the plan does have a significantly positive and persistent impact on sales that is lower in the fourth quarter. Overall, the results in Tables 6,7 , and 8 indicate that, while relative income growth is important in explaining store sales, the implementation of the performance-based incentive plan resulted in sales gains that increase over time and that these gains are lower when there are more temporary salespersons.

\section{Insert Table 8 Here}

We consider next the possibility that sales managers and consultants in the plan stores increased the consumption of sales-related resources to increase sales. The relation of these costs to the plan's sales impact is examined in Table 9. One concern is that sales personnel maintain additional inventories on hand to promote sales once the incentive plan is implemented. The regression estimates reported in the left column indicate that there was little difference in inventory turnover rates before and after the plan's implementation.

There is also the possibility that sales personnel give more price breaks (they are authorized to discount merchandise up to $10 \%$ ), sell less profitable merchandise, or encourage customers to purchase (and then return) more goods than they need. All of these factors suggest that gross margins erode after the plan's implementation. There is no evidence, however, of any decrease in gross margins as the regression results reported in the middle column of Table 9 indicate that the cost of goods sold as a percentage of sales remains unchanged after plan implementation.

Additional sales could also be generated by consuming other company resources. Because data for support activity expenses (such as stock handling, security, administration) 
were not available to us for the first 12 months of our sample period, this regression was estimated with data for the remaining 54 months. Results reported in the right column indicate that support expenses as a percentage of sales did not change significantly after the plan's implementation. Taken together the results in Table 9 reveal that the sales gains documented above are not obtained because of inventory accumulation, margin erosion, or support cost inflation.

\section{Insert Table 9 Here}

In summary, after considering factors such as income growth, margin reduction, and resource consumption that may impact sales, the empirical evidence indicates that sales gains occur on the implementation of the incentive plan. The signs of the estimated coefficients are remarkably robust across models, all indicating that sales gains increase over time and lower gains obtain in the periods when the proportion of temporary employees is high, although the statistical significance of the tests differs across models. Overall, the evidence is consistent with the notion that the effects of incentives are considered by sales consultants in their decisions to provide better customer service.

\section{Concluding Remarks}

There has been considerable interest in the management accounting literature on the theoretical derivation of optimal incentive contracts in a principal-agent setting. A fundamental assumption in most agency-theoretic models is that the agents will optimally trade off expected increase in incentive compensation against disutility for greater effort. There have not been many 
attempts, however, to test whether this assumption is supported by empirical observations over a long span of time. This need for empirical validation is particularly salient because the richer, more complex, theoretical models that consider multi-period consequences of incentive contracts impose a great cognitive burden on the agent's ability to assess effects that are not immediately evident.

In this paper we have examined the impact of a performance-based compensation plan at a firm that operates numerous retail outlets. We find that the implementation of the plan is associated with increases in sales that persist and increase over time. As such this finding supports the basic agency-theoretic assumption that output increases when agents are rewarded for performance. There is also strong evidence that the impact of the incentive contract is lower when the proportion of temporary workers is higher. These observations are consistent with the permanent sales consultants (but not the temporary workers) optimally assessing the multi-period implications of working to develop long-term service relation with customers, or to learn how to perform their task more efficiently, which translates into future sales gain.

A caveat that must be recognized, however, stems from the limitation that field-based research imposes on our ability to control all other factors bearing on the phenomenon being studied, and also on our ability to obtain data on such other factors to assess their influence on our results. The increase in sales gains documented in our study may be caused by multi-period effect of incentives on the consultants' allocation of effort, or by possibilities such as performance-based incentives attracting workers with higher intrinsic ability, improving the average performance of the salesforce over time. Data available to us for this study do not allow us to discriminate between these alternative ways in which provision of incentives can improve organizational performance. Our study is also limited to an analysis of the impact of the 
compensation plan on sales and some related resources only. We have not examined the overall impact of the plan on the firm's performance to assess whether it is the optimal plan. Notwithstanding these caveats, the study illustrates the value of field-based research to help evaluate theoretical predictions that ultimately are intended to inform us on the behavior of economic agents in the field. 
Table 1: Average size of retail outlets by incentive plan existence (means, with medians in parentheses below).

\begin{tabular}{lccc}
\hline & $\begin{array}{l}\text { Stores } \\
\text { with plan }\end{array}$ & $\begin{array}{l}\text { Stores } \\
\text { without plan }\end{array}$ & $\begin{array}{l}\text { Statistical tests } \\
\text { of difference }\end{array}$ \\
\hline SQFEET (000's) 1987-88 & 227.52 & 220.42 & $p(t)=0.88$ \\
SALES (millions) 1987-88 & $(187.08)$ & $(187.08)$ & $p(z)=0.66$ \\
SALES (millions) 1990-91 & $\$ 43.03$ & $\$ 34.51$ & $p(t)=0.30$ \\
& $(\$ 35 .(1)$ & $(\$ 22.91)$ & $p(z)=0.23$ \\
Number of stores & $\$ 51.98$ & $\$ 38.15$ & $p(t)=0.14$ \\
& $(\$ 43.03)$ & $(\$ 28.10)$ & $p(z)=0.19$
\end{tabular}

The mean values reported in the table are disguised by multiplying by a scalar. The statistical tests are not affected by this transformation.

Stores that have implemented the performance-based plan as of the end of the sample period are classified as 'stores with plan'.

$\operatorname{pi}(t) \quad=$ probability that the means of the two groups are equal.

$p(z) \quad=$ probability that the medians of the two groups are equal.

SQFEET = square footage of retail store in fiscal year February 1987 to January 1988.

SALES = annual sales of retail store in fiscal year (in thousand dollars). 
Table 2. Mean financial ratios for retail outlets by incentive plan existence.

\begin{tabular}{|c|c|c|c|c|}
\hline Financial ratios & & $\begin{array}{l}\text { Stores } \\
\text { with plan }\end{array}$ & $\begin{array}{l}\text { Stores } \\
\text { without plan }\end{array}$ & $\begin{array}{l}\text { Statistical tests } \\
\text { of difference }\end{array}$ \\
\hline Beg. inventory & $1987-88$ & 4.220 & 4.220 & $p(t)=0.45$ \\
\hline Sales & $1990-91$ & 4.243 & 4.460 & $p(t)=0.24$ \\
\hline Cost of sales & 1987-88 & 0.609 & 0.608 & $p(t)=0.80$ \\
\hline Sales & $1990-91$ & 0.616 & 0.612 & $p(t)=0.38$ \\
\hline Support expenses & $1987-88$ & 0.034 & 0.036 & $p(t)=0.21$ \\
\hline Sales & $1990-91$ & 0.028 & 0.033 & $p(t)=0.002$ \\
\hline
\end{tabular}

The mean values reported in the table are disguised by multiplying by a scalar. The statistical tests are not affected by this transformation.

Stores that have implemented the performance-based plan as of the end of the sample period are classified as 'stores with plan'.

$p(t)=$ probability that the means of the two groups are equal.

Support expenses include indirect labor costs for stocking, cleaning, wrapping, and monitoring merchandise. 
Table 3: WLS estimates of impact of incentive plan on sales (f-statistic in parentheses); $n=990$, 15 stores for 66 months from February 1986 to July 1991.

$$
\begin{aligned}
& S A L E S_{s t}=\sum_{s=1}^{15}\left(\alpha_{s} D_{\mathrm{x}}+\beta_{s} D_{s} A V G \operatorname{COS} A L_{t}\right)+\lambda_{1} D_{s l}^{P} S A L E S 86_{s}+\lambda_{2} D_{s t}^{P} D_{s t}^{Y} S A L E S 86_{x} \\
& +\lambda_{3} D_{s t}^{P} D_{s}^{Q} S A L E S 86_{s}+\lambda_{4} D_{s t}^{P} A V G \operatorname{COS} A L_{t}+\lambda_{5} D_{s t}^{P} D_{s t}^{\gamma} A V G \operatorname{COS} A L_{l} \\
& +\lambda_{6} D_{\mathrm{st}}^{P} D_{\mathrm{st}}^{Q} A V G \operatorname{COS} A L_{\mathrm{r}}+\varepsilon_{\mathrm{st}}
\end{aligned}
$$

\begin{tabular}{|c|c|c|c|c|c|}
\hline \multirow[b]{2}{*}{ Variable } & \multirow[b]{2}{*}{ Parameter } & \multirow{2}{*}{$\begin{array}{l}\text { Expected } \\
\text { sign }\end{array}$} & \multicolumn{2}{|c|}{ Parameter estimate } & \multirow[b]{2}{*}{3} \\
\hline & & & 1 & 2 & \\
\hline$D_{\mathrm{s}}^{P} S A L E S 86$ & $\lambda_{1}$ & + & - & $\begin{array}{l}0.102 \\
(8.89)\end{array}$ & $\begin{array}{r}0.063 \\
(3.43)\end{array}$ \\
\hline$D_{s t}^{P} D_{s r}^{Y} S A L E S 86$ & $\lambda_{2}$ & + & - & $\begin{array}{c}0.023 \\
(1.77)\end{array}$ & $\begin{array}{r}-0.005 \\
(-0.28)\end{array}$ \\
\hline$D_{\mathrm{s}}^{P} D_{\mathrm{M}}^{Q} S A L E S 86$ & $\lambda_{3}$ & - & - & $\begin{array}{l}-0.026 \\
(-2.13)\end{array}$ & $\begin{array}{l}-0.004 \\
(-0.25)\end{array}$ \\
\hline$D_{s t}^{P} A V G C O S A L$ & $\lambda .4$ & + & $\begin{array}{r}0.105 \\
(8.94)\end{array}$ & - & $\begin{array}{c}0.054 \\
(2.82)\end{array}$ \\
\hline$D_{s}^{P} D_{s f}^{\gamma} A V G \operatorname{Cos} A L$ & $\lambda_{5}$ & + & $\begin{array}{r}0.051 \\
(3.73)\end{array}$ & - & $\begin{array}{r}0.050 \\
(2.56)\end{array}$ \\
\hline$D_{s t}^{P} D_{s t}^{Q} A V G \cos A L$ & $\lambda_{6}$ & - & $\begin{array}{l}-0.056 \\
(-4.72)\end{array}$ & - & $\begin{array}{r}-0.035 \\
(-1.87)\end{array}$ \\
\hline $\begin{array}{l}p(\text { model }) \\
\text { Adjusted } R^{2}\end{array}$ & & & $\begin{array}{l}0.0001 \\
0.9781\end{array}$ & $\begin{array}{l}0.0001 \\
0.9773\end{array}$ & $\begin{array}{l}0.0001 \\
0.9786\end{array}$ \\
\hline $\begin{array}{l}P\left(\lambda_{1}=\lambda_{4}=0\right) \\
p\left(\lambda_{2}=\lambda_{5}=0\right) \\
p\left(\lambda_{3}=\lambda_{6}=0\right)\end{array}$ & & & & & $\begin{array}{l}0.0001 \\
0.0027 \\
0.0068\end{array}$ \\
\hline
\end{tabular}

$$
\begin{array}{ll}
D_{v} & =1 \text { if store } s, \text { otherwise zero. } \\
D_{s t}^{p} & =1 \text { if store is on the incentive plan, otherwise zero. } \\
D_{s t}^{r} & =1 \text { if store has been on the incentive plan for at least one year, otherwise zero. } \\
D_{s}^{Q} & =1 \text { if fourth quarter of fiscal year, otherwise zero. } \\
S A L E S 86 & =\text { average monthly store sales in fiscal year 1986-87. } \\
A V G \operatorname{CoS} A L & =\text { average sales of } 19 \text { stores that did not implement incentive plan. } \\
p(\text { model }) & =\text { probability that all model coefficients are zero. } \\
p\left(\lambda_{i}=\lambda_{j}=0\right) & =\text { probability that coefficients } \lambda_{i} \text { and } \lambda_{j} \text { are both zero. }
\end{array}
$$


Table 4. WLS estimates of impact of incentive plan on relative sales (t-statistic in parentheses); $\mathrm{n}=990,15$ stores for 66 months from February 1986 to July 1991.

$S A L E S_{s t} / A V G \operatorname{Cos} A L_{t}=\sum_{s=1}^{15} \beta_{s} D_{s}+\lambda_{1} D_{s t}^{P}+\lambda_{2} D_{s t}^{P} D_{s t}^{Y}+\lambda_{3} D_{s t}^{P} D_{s t}^{Q}+\varepsilon_{s t}$

\begin{tabular}{lccc}
\hline Variable & Parameter & Expected sign & Parameter estimate \\
\hline$D_{s t}^{P}$ & $\lambda_{1}$ & + & 0.093 \\
$D_{s t}^{P} D_{s t}^{Y}$ & $\lambda_{2}$ & + & $(6.78)$ \\
$D_{s t}^{P} D_{\mathrm{st}}^{Q}$ & $\lambda_{3}$ & - & 0.050 \\
& & & $(2.78)$ \\
$p($ model $)$ & & & -0.016 \\
Adjusted $R^{2}$ & & & 0.0001 \\
\hline
\end{tabular}

$D_{\mathrm{s}} \quad=1$ if store $s$, otherwise zero.

$D_{s t}^{P} \quad=1$ if store is on the incentive plan, otherwise zero.

$D_{s r}^{\gamma} \quad=1$ if store has been on the incentive plan for at least one year, otherwise zero.

$D_{s i}^{Q} \quad=1$ if fourth quarter of fiscal year, otherwise zero.

SALES86 = average monthly store sales in fiscal year 1986-87.

$A V G \operatorname{COS} A L=$ average sales of 19 stores that did not implement incentive plan.

$p$ (model) $\quad=$ probability that all model coefficients are zero. 
Table 5. Average annual personal income growth rate for county of store location by incentive plan existence

\begin{tabular}{|c|c|c|c|}
\hline & $\begin{array}{l}\text { Stores } \\
\text { with plan }\end{array}$ & $\begin{array}{l}\text { Stores } \\
\text { without plan }\end{array}$ & $\begin{array}{l}\text { Statistical tests } \\
\text { of difference }\end{array}$ \\
\hline $\begin{array}{l}\text { Growth rate 1984-87, Mean } \\
\text { (Median) }\end{array}$ & $\begin{array}{c}0.067 \\
(0.063)\end{array}$ & $\begin{array}{c}0.057 \\
(0.060)\end{array}$ & $\begin{array}{l}p(t)=0.1702 \\
p(z)=0.2102\end{array}$ \\
\hline $\begin{array}{l}\text { Growth rate 1988-90, Mean } \\
\text { (Median) }\end{array}$ & $\begin{array}{l}0.072 \\
(0.070)\end{array}$ & $\begin{array}{l}0.059 \\
(0.054)\end{array}$ & $\begin{array}{l}p(t)=0.0129 \\
p(z)=0.0515\end{array}$ \\
\hline Number of stores & 15 & 19 & \\
\hline
\end{tabular}

Stores that have implemented the performance-based plan as of the end of 1990 are classified as ‘stores with plan'.

$p(t) \quad=$ probability that the means of the two groups are equal.

$p(z) \quad=$ probability that the medians of the two groups are equal.

Growth rate $=$ annual growth rate in county personal income. 
Table 6. WLS estimates of impact of incentive plan and income growth on relative sales ((statistic in parentheses); $\mathrm{n}=990,15$ stores for 66 months from February 1986 to July 1991.

\begin{tabular}{|c|c|c|c|c|c|}
\hline \multirow[b]{2}{*}{ Variable } & \multirow[b]{2}{*}{ Parameter } & \multirow{2}{*}{$\begin{array}{l}\text { Expected } \\
\text { sign }\end{array}$} & \multicolumn{2}{|c|}{ Parameter estimate } & \multirow[b]{2}{*}{3} \\
\hline & & & 1 & 2 & \\
\hline \multirow[t]{2}{*}{$R G I N C$} & $y$ & + & 0.957 & 0.963 & 0.737 \\
\hline & & & $(11.97)$ & $(12.26)$ & $(7.91)$ \\
\hline$D_{\mathrm{st}}^{P}$ & $\lambda_{1}$ & + & - & $\begin{array}{l}0.059 \\
(4.70)\end{array}$ & $\begin{array}{r}0.077 \\
(0.40)\end{array}$ \\
\hline$D_{s t}^{P} D_{s t}^{Y}$ & $\lambda_{2}$ & + & - & $\begin{array}{l}0.035 \\
(2.22)\end{array}$ & $\begin{array}{l}0.333 \\
(1.63)\end{array}$ \\
\hline$D_{s t}^{P} D_{s z}^{Q}$ & $i_{3}$ & - & - & $\begin{array}{l}-0.015 \\
(-1.10)\end{array}$ & $\begin{array}{l}0.212 \\
(0.72)\end{array}$ \\
\hline$D_{21}^{p} * R G I N C$ & $i_{4}$ & + & $\begin{array}{c}0.055 \\
(4.58)\end{array}$ & - & $\begin{array}{l}-0.005 \\
(-0.03)\end{array}$ \\
\hline$D_{v t}^{P} D_{s t}^{Y} * R G I N C$ & $i_{5}$ & + & $\begin{array}{l}0.031 \\
(2.10)\end{array}$ & - & $\begin{array}{r}-0.269 \\
(-1.41)\end{array}$ \\
\hline$D_{s t}^{P} D_{s t}^{Q} * R G I N C$ & $i_{6}$ & - & $\begin{array}{r}-0.014 \\
(-1.10)\end{array}$ & - & $\begin{array}{r}-0.215 \\
(0.78)\end{array}$ \\
\hline $\begin{array}{l}p \text { (model) } \\
\text { Adjusted } R^{2}\end{array}$ & & & $\begin{array}{l}0.0001 \\
0.9630\end{array}$ & $\begin{array}{l}0.0001 \\
0.9633\end{array}$ & $\begin{array}{l}0.0001 \\
0.9643\end{array}$ \\
\hline $\begin{array}{l}p\left(\lambda_{1}=\lambda_{4}=0\right) \\
p\left(\lambda_{2}=\lambda_{5}=0\right) \\
p\left(\lambda_{3}=\lambda_{6}=0\right)\end{array}$ & & & & & $\begin{array}{l}0.0001 \\
0.0071 \\
0.3483\end{array}$ \\
\hline
\end{tabular}

\footnotetext{
RGINC = relative growth in personal income of county of store location.

$D_{s} \quad=1$ if store $s$, otherwise zero.

$D_{s t}^{P} \quad=1$ if store is on the incentive plan, otherwise zero.

$D_{s t}^{\gamma} \quad=1$ if store has been on the incentive plan for at least one year, otherwise zero.

$D_{s}^{Q} \quad=1$ if fourth quarter of fiscal year, otherwise zero.

$p$ (model) $\quad=$ probability that all model coefficients are zero.

$p\left(\lambda_{i}=\lambda_{j}=0\right)=$ probability that coefficients $\lambda_{i}$ and $\lambda_{j}$ are both zero.
} 
Table 7. WLS estimates of impact of incentive plan and income growth on sales (t-statistic in parentheses); $\mathrm{n}=990,15$ stores for 66 months from February 1986 to July 1991

$$
\begin{aligned}
& S A L E S_{s t}=\sum_{s=1}^{15}\left(\alpha_{s} D_{x}+\beta_{x} D_{s} A V G \operatorname{Cos} A L_{t}\right)+i A V G \cos A L_{t} R G I N C_{x t}+i_{1} D_{s t}^{p} A V G \operatorname{Cos} A L_{t} \\
& +\lambda_{2} D_{s t}^{P} D_{u}^{Y} A V G \operatorname{Cos} A L_{t}+\lambda_{3} D_{s t}^{p} D_{s t}^{Q} A V G \operatorname{Cos} A L_{t}+\lambda_{4} D_{s t}^{P} A V G \operatorname{COS} A L_{1} R G I N C_{n t} \\
& +\lambda_{5} D_{s i}^{P} D_{s t}^{\gamma} A V G \operatorname{CoS} A L_{t} R G I N C_{s t}+\lambda_{b} D_{s t}^{p} D_{s}^{Q} A V G \operatorname{Cos} A L_{r} R G I N C_{s t}+\varepsilon_{s t}
\end{aligned}
$$

\begin{tabular}{|c|c|c|c|c|c|}
\hline \multirow[b]{2}{*}{ Variable } & \multirow[b]{2}{*}{ Parameter } & \multirow{2}{*}{$\begin{array}{l}\text { Expected } \\
\text { sign }\end{array}$} & \multicolumn{2}{|c|}{ Parameter estimate } & \multirow[b]{2}{*}{3} \\
\hline & & & 1 & 2 & \\
\hline$R G I N C * A V G C O S A L$ & 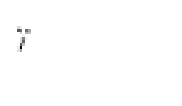 & + & $\begin{array}{r}0.871 \\
(5.13)\end{array}$ & $\begin{array}{r}0.891 \\
(5.47)\end{array}$ & $\begin{array}{c}1.039 \\
(5.69)\end{array}$ \\
\hline$D_{s t}^{P} * A V G \operatorname{Cos} A L$ & $i_{1}$ & + & - & $\begin{array}{r}0.073 \\
(5.63)\end{array}$ & $\begin{array}{r}0.111 \\
(0.55)\end{array}$ \\
\hline$D_{s}^{P} D_{\mathrm{x}}^{Y} * A V G \operatorname{Cos} A L$ & $i_{2}$ & + & - & $\begin{array}{r}0.030 \\
(2.25)\end{array}$ & $\begin{array}{l}-0.032 \\
(-0.15)\end{array}$ \\
\hline$D_{s t}^{p} D_{s t}^{Q} * A V G \cos A L$ & $\lambda$ & - & - & $\begin{array}{r}-0.054 \\
(-4.66)\end{array}$ & $\begin{array}{c}0.468 \\
(2.04)\end{array}$ \\
\hline$D_{s t}^{p} * A V G C O S A L * R G I N C$ & $i_{4}$ & + & $\begin{array}{c}0.068 \\
(5.51)\end{array}$ & - & $\begin{array}{l}-0.043 \\
(-0.22)\end{array}$ \\
\hline$D_{s t}^{P} D_{x t}^{\gamma} * A V G C O S A L * R G I N C$ & i.s & + & $\begin{array}{l}0.027 \\
(2.15)\end{array}$ & - & $\begin{array}{r}0.061 \\
(0.31)\end{array}$ \\
\hline$D_{s}^{P} D_{x i}^{Q} * A V G \operatorname{Cos} A L * R G I N C$ & $i_{h}$ & - & $\begin{array}{r}-0.051 \\
(-4.69)\end{array}$ & - & $\begin{array}{r}-0.491 \\
(-2.29)\end{array}$ \\
\hline $\begin{array}{l}P \text { (model) } \\
\text { Adjusted } R^{2}\end{array}$ & & & $\begin{array}{l}0.0001 \\
0.9789\end{array}$ & $\begin{array}{l}0.0001 \\
0.9790\end{array}$ & $\begin{array}{l}0.0001 \\
0.9792\end{array}$ \\
\hline $\begin{array}{l}p\left(\lambda_{1}=\lambda_{4}=0\right) \\
p\left(\lambda_{2}=\lambda_{3}=0\right) \\
p\left(\lambda_{3}=\lambda_{6}=0\right)\end{array}$ & & & & & $\begin{array}{l}0.0001 \\
0.0482 \\
0.0001\end{array}$ \\
\hline
\end{tabular}


Table 8. WLS estimates of impact of incentive plan and income growth on sales (r-statistic in parentheses); $\mathrm{n}=990,15$ stores for 66 months from February 1986 to July 1991

$$
\begin{aligned}
& S A L E S_{21}=\sum_{x=1}^{15}\left(\alpha_{s} D_{s}+\beta_{s} D_{s} A V G \operatorname{COS} A L_{l} R G I N C_{s l}\right)+\lambda_{1} D_{s r}^{P} S A L E S 8 \sigma_{x} \\
& +\lambda_{2} D_{s r}^{p} D_{s r}^{\gamma} S A L E S 8 \sigma_{\mathrm{s}}+\lambda_{3} D_{v t}^{p} D_{s}^{Q} S A L E S 86_{s}+\lambda_{4} D_{x t}^{p} A V G \operatorname{COS} A L_{t} R G I N C_{s t} \\
& +i_{s} D_{s t}^{p} D_{s t}^{\gamma} A V G \operatorname{CoS} A L_{1} R G I N C_{s t}+\lambda_{D} D_{s t}^{p} D_{s}^{Q} A V G \operatorname{COS} A L_{t} R G I N C_{s t}+\varepsilon_{s t}
\end{aligned}
$$

\begin{tabular}{|c|c|c|c|c|c|}
\hline \multirow[b]{2}{*}{ Variable } & \multirow[b]{2}{*}{ Parameter } & \multirow{2}{*}{$\begin{array}{l}\text { Expected } \\
\text { sign }\end{array}$} & \multicolumn{2}{|c|}{ Parameter estimate } & \multirow[b]{2}{*}{3} \\
\hline & & & 1 & 2 & \\
\hline$D_{s}^{p} * S A L E S \& d$ & $i_{1}$ & + & - & $\begin{array}{r}0.075 \\
(6.95)\end{array}$ & $\begin{array}{c}0.056 \\
(3.14)\end{array}$ \\
\hline$D_{s}^{\mu} D_{s}^{\gamma} * S A L E S 86$ & $i_{2}$ & + & - & $\begin{array}{l}0.005 \\
(0.45)\end{array}$ & $\begin{array}{r}-0.009 \\
(-0.53)\end{array}$ \\
\hline$D_{s}^{p} D_{s t}^{Q} * S A L E S 86$ & $\lambda_{3}$ & - & - & $\begin{array}{l}-0.029 \\
(-2.52)\end{array}$ & $\begin{array}{r}-0.001 \\
(-0.10)\end{array}$ \\
\hline$D_{x *}^{p} * A V G C O S A L * R G I N C$ & 1.4 & + & $\begin{array}{c}0.067 \\
(6.42)\end{array}$ & - & $\begin{array}{c}0.026 \\
(1.50)\end{array}$ \\
\hline$D_{v i}^{p} D_{s t}^{\gamma} * A V G C O S A L * R G I N C$ & $i_{5}$ & + & $\begin{array}{c}0.020 \\
(1.68)\end{array}$ & - & $\begin{array}{c}0.023 \\
(1.34)\end{array}$ \\
\hline$D_{s t}^{p} D_{s t}^{Q} * A V G \cos A L * R G I N C$ & $i_{n}$ & - & $\begin{array}{r}-0.050 \\
(-4.74)\end{array}$ & - & $\begin{array}{l}-0.036 \\
(-2.11)\end{array}$ \\
\hline $\begin{array}{l}p \text { (model) } \\
\text { Adjusted } R^{2}\end{array}$ & & & $\begin{array}{l}0.0001 \\
0.9799\end{array}$ & $\begin{array}{l}0.0001 \\
0.9796\end{array}$ & $\begin{array}{l}0.0001 \\
0.9786\end{array}$ \\
\hline $\begin{array}{l}p\left(\lambda_{1}=\lambda_{4}=0\right) \\
p\left(\lambda_{2}=\lambda_{5}=0\right) \\
p\left(\lambda_{3}=\lambda_{6}=0\right)\end{array}$ & & & & & $\begin{array}{l}0.0001 \\
0.3195 \\
0.0036\end{array}$ \\
\hline
\end{tabular}

\footnotetext{
RGINC = relative growth in personal income of county of store location.

$D_{v} \quad=1$ if store $s$, otherwise zcro.

$D_{s}^{\mu} \quad=1$ if store is on the incentive plan, otherwise zero.

$D_{s}^{r} \quad=1$ if store has been on the incentive plan for at least one year, otherwise zero.

$D_{v}^{Q} \quad=1$ if fourth quarter of fiscal year, otherwise zero.

SALES86 = average monthly store sales in 1986 .

$A V G \operatorname{COS} A L=$ average sales of 19 stores that did not implement incentive plan.

$p$ (model) $=$ probability that all model coefficients are zero.

$p\left(\lambda_{i}=\lambda_{j}=0\right)=$ probability that coefficients $\lambda_{i}$ and $\lambda_{j}$ are both zero.
} 
Table 9. Impact of incentive plan on expenses ( $t$-statistics in parentheses); $\mathrm{n}=990,15$ stores for 66 months from February 1986 to July 1991.

$y_{s t j}=\alpha_{j}+\sum_{s=2}^{15} \beta_{s j} D_{s}+\sum_{t=2}^{66} \delta_{t j} D_{t}^{T}+\gamma_{1 j} D_{s t}^{P}+\gamma_{2 j} D_{s t}^{P} D_{s t}^{Y}+\gamma_{3 j} D_{s t}^{P} D_{s t}^{Q}+e_{s t j}, \quad j=1,2,3$

\begin{tabular}{|c|c|c|c|}
\hline & $\frac{\text { Beg. inventory }_{s t}}{\text { Sales }_{s t} / 100}$ & $\frac{\text { Cost of } \text { sales }_{s t}}{\text { Sales }_{s t} / 100}$ & $\frac{\text { Support expenses }_{s t}}{\text { Sales }_{s t} / 100}$ \\
\hline$\gamma_{1 j}$ & $\begin{array}{l}7.610 \\
(0.66)\end{array}$ & $\begin{array}{l}0.222 \\
(0.41)\end{array}$ & $\begin{array}{l}0.017 \\
(0.26)\end{array}$ \\
\hline$\gamma_{2 j}$ & $\begin{array}{c}16.902 \\
(1.56)\end{array}$ & $\begin{array}{l}-0.084 \\
(-0.17)\end{array}$ & $\begin{array}{l}-0.011 \\
(-0.19)\end{array}$ \\
\hline$\gamma_{3 j}$ & $\begin{array}{c}0.476 \\
(0.02)\end{array}$ & $\begin{array}{c}1.175 \\
(1.19)\end{array}$ & $\begin{array}{c}-0.018 \\
(0.16)\end{array}$ \\
\hline Adjusted $R^{2}$ & 0.7253 & 0.5708 & 0.8588 \\
\hline
\end{tabular}

$D_{t}^{T}=1$ if month $t$, otherwise 0 .

See Tables 2 and 3 for other variable definitions. 


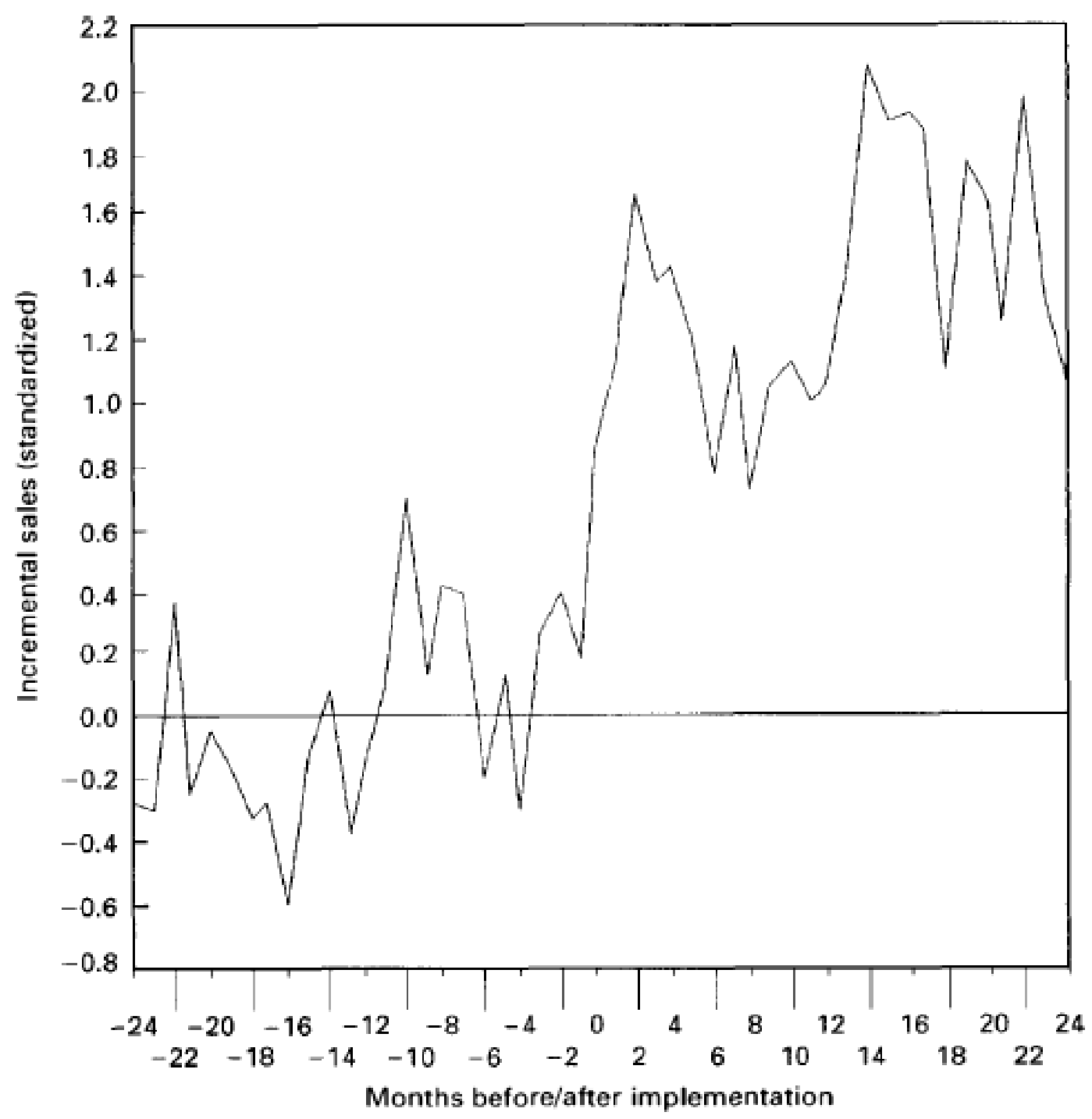

Model: $\operatorname{SALES}_{\star}=\alpha_{1}+\beta_{1}$ AVGCOSAL $_{4}+\varepsilon_{\star} \quad$ for each $s=1, \ldots 15$, where

SALES $_{\mathrm{st}}=$ Sales of store $\mathrm{s}$ in month $\mathrm{t}$,

AVGCOSAL $=$ Average monthly sales of the 19 company stores in the same geographic region that did not implement the incentive plan, and

$\hat{\boldsymbol{\alpha}}_{\mathrm{s}}$ and $\hat{\boldsymbol{\beta}}_{\mathrm{s}}$ are estimated using monthly data for 24 months prior to the plan implementation.

Incremental Sales, $\left(\right.$ standardized) $=\sum_{k=1}^{15}\left(\right.$ SALES $_{4}-\hat{\alpha}_{s}-\hat{\beta}_{s}$ AVGCOSAL $\left._{\mathbf{3}}\right) / 15 \sqrt{\operatorname{Var}\left(\varepsilon_{x}\right)}$ for $\mathrm{t}=-24, \ldots-1,0,1, \ldots 24$, where $\mathrm{t}=0$ is the month of implementation.

Figure 1. Plot of average incremental sales for 15 stores centered around each store's own date of plan implementation. 


\section{References}

Antle, R. and A. Smith, 1986, An empirical investigation of the relative performance evaluation of corporate executives, Journal of Accounting Research 24, 1-39.

Awasthi, V. and J. Pratt, 1990, The effect of monetary incentives on effort and decision performance: The role of cognitive characteristics, The Accounting Review 65, 797-811.

Ashton, R.H., 1990, Pressure and performance in accounting decision settings: Paradoxical effects of incentives, feedback and justification, Journal of Accounting Research 28, Suppl., 148-180.

Baker, B., 1990, The other Nordstrom, Los Angeles Times, Feb. 4, D1.

Baker, G.P., M.C. Jensen, and K.J. Murphy, 1988, Compensation and incentives: Practice vs. theory, Journal of Finance 43, 593-616.

Banker, R.D. and S.M. Datar, 1989, Sensitivity, precision and linear aggregation of signals for performance evaluation, Journal of Accounting Research 27, 21-39.

Barmash, I., 1989, Bloomingdale's in Manhattan to put staff on commission, New York Times, July 6.

Basu, A.K., R. Lai, B. Srinivasan, and R. Staelin, 1985, Salesforce compensation plans: An agency theoretical perspective, Marketing Science 4, 267-291.

Belsley, D.A., E. Kuh, and R.E. Welsch, 1980, Regression diagnostics (Wiley, New York, NY).

Benston, G., 1985, The self-serving management hypothesis: Some evidence, Journal of Accounting and Economics 7, 67-84. 
Bivins, J., 1989, Focus on compensation: (1) Commissions and more, (2) New study: How stores are paying, (3) Keys to measuring compensation programs, and (4) How Younkers satisfaction plus' program works, Stores, Sept. 25-30.

Christie, A.A., 1987, On cross-sectional analysis in accounting research, Journal of Accounting and Economics 9, 231-258.

Clawson, D., 1980, Bureaucracy and the labor process (Monthly Review Press, New York, NY).

Condry, J., 1977, Enemies of exploration: Self initiated versus other initiated learning, Journal of Personality and Social Psychology 35, 459-477.

Coopers and Lybrand, 1992, Compensation planning for 1993 (New York, NY).

Coughlan, A.T. and C. Narasimhan, 1992, An empirical analysis of sales-force compensation plans, Journal of Business 65, 93-121.

Coughlan, A.T. and R.M. Schmidt, 1985, Executive compensation, management turnover and firm performance: An empirical investigation, Journal of Accounting and Economics 7, 43-66.

Deci, E.L. and R.M. Ryan, 1985, Intrinsic motivation and self-determination in human behavior (Plenum Press, New York, NY).

Doran, H.E. and W.E. Griffiths, 1983, On the relative efficiency of estimators which include the initial observations in the estimation of seemingly unrelated regressions with first-order autoregressive disturbances, Journal of Econometrics 23, 165-191.

Gallagher, R., 1992, Editor's page: Compensation, Stores, Aug. 6.

Gibbons, R. and K.J. Murphy, 1990, Relative performance evaluation for chief executive officers, Industrial and Labor Relations Review 43, 30S-73S. 
Gibbs, M., 1995, Incentive compensation in a corporate hierarchy, Journal of Accounting and Economics 19, 247-277.

Ginsberg, S., 1989, Commission sales growing in big stores, Women's Wear Daily, Oct. 4, 1.

Glesjer, H., 1969, A new test for heteroscedasticity, Journal of the American Statistical Association 64, 316-323.

Guzzo, R.A., R.D. Jette, and R.A. Katzell, 1985, The effects of psychologically-based intervention programs on worker productivity: A meta-analysis, Personnel Psychology, Summer, 275-291.

Hogarth, R.M., B.J. Gibbs, C.R.M. McKenzie, and M.A. Marquis, 1991, Learning from feedback: Exactingness and incentives, Journal of Experimental Psychology: Learning, Memory, and Cognition 17, 734-752.

Holmström, B., 1982, Moral hazard in teams, Bell Journal of Economics 13, 324-340.

Holmström, B. and P. Milgrom, 1991, Multitask principal-agent analyses: Incentive contracts, asset ownership, and job design, Journal of Law, Economics and Organizations 7, 24-52.

Holthausen, R.W., D.F. Larcker, and R.G. Sloan, 1995, Business unit innovation and the structure of executive compensation, Journal of Accounting and Economics 19, 279-313.

Homans, G.C., 1952, Group factors in worker productivity, in: G.E. Swanson, T.M. Newcomb, and E.L. Hartley, eds., Readings in social psychology, Rev. ed. (Holt, New York, NY) 637-649.

Jenkins, G.D., 1986, Financial incentives, in: E.A. Locke, ed., Generalizing from laboratory to field settings (Heath, Lexington, MA).

Jensen, M.C. and K.J. Murphy, 1990, Performance pay and top-management incentives, Journal of Political Economy 98, 225-264. 
Jensen, M.C. and J.L. Zimmerman, 1985, Management compensation and the managerial labor market, Journal of Accounting and Economics 7, 3-9.

John, G. and B. Weitz, 1989, Salesforce compensation: An empirical investigation of factors related to use of salary versus incentive compensation, Journal of Marketing Research $26,1-14$.

Johnston, J., 1984, Econometric methods, 3rd ed. (McGraw-Hill, New York, NY).

Kanfer, R. and P.L. Ackerman, 1989, Motivation and cognitive abilities: An integrative/aptitudetreatment interaction approach to skill acquisition, Journal of Applied Psychology 74, 657-690.

Kmenta, J. and R.F. Gilbert, 1970, Estimation of seemingly unrelated regressions with autoregressive disturbance, Journal of the American Statistical Association 65, 186-197.

Kohn, A., 1988, Incentives can be bad for business, INC., Jan., 93-94.

Koselka, R., 1991, Fading into history, Forbes, Aug. 19, 70-71.

Lai, R. and R. Staelin, 1986, Salesforce compensation plans in environments with asymmetric information, Marketing Science 5, 179-198.

Lambert, R. and D. Larcker, 1987, An analysis of the use of accounting and market measures of performance in executive compensation contracts, Journal of Accounting Research 25, 85-129.

Latham, G.P. and D.L. Dossett, 1978, Designing incentive plans for union employees: A comparison of continuous and variable reinforcement schedules, Personnel Psychology $31,47-61$.

Lawler, E.E., 1981, Pay and organizational development (Addison-Wesley, Reading, MA). 
Lepper, M.R., D. Greene, and R.E. Nisbett, 1973, Undermining children's intrinsic interest with extrinsic reward: A test of the overjustification hypothesis, Journal of Personality and Social Psychology 28, 129-137.

Levine, F.M. and G. Fasnacht, 1974, Token rewards may lead to token learning, American Psychologist, 29, 816-820.

Libby, R. and M.G. Lipe, 1992, Incentives, efforts, and the cognitive processes involved in accounting-related judgments, Journal of Accounting Research 30, 249-273.

Lloyd, B., 1989, Rich's total sales force going on commission, Daily News Record, Feb. 22, 11.

Locke, E., J.F. Bryan, and L.M. Kendall, 1968, Goals and intentions as mediators of the effects of monetary incentives and behavior, Journal of Applied Psychology 52, 104-121.

McGraw, K.O., 1978, The detrimental effects of reward on performance: A literature review and a prediction model, in: M.R. Lepper and D. Greene, eds., The hidden costs of reward (Erlbaum, Hillside, NJ).

Milgrom, P. and J. Roberts, 1992, Economics, organization and management (Prentice-Hall, Englewood Cliffs, NJ).

Murphy, K.J., 1985, Corporate performance and managerial remuneration: An empirical analysis, Journal of Accounting and Economics 7, 11-42.

Murphy, K.J., 1986, Incentives, learning, and compensation: A theoretical and empirical investigation of managerial labor contracts, Rand Journal of Economics 17, 59-76.

Park, R.E. and B.M. Mitchell, 1980, Estimating the autocorrelated error model with trended data, Journal of Econometrics 13, 185-201. 
Pearce, J.L., W.B. Stevenson, and J.L. Perry, 1985, Managerial compensation based on organization performance: A time series analysis of the effects of merit pay, Academy of Management Journal 28, 261-278.

Prais, S.J. and C.B. Winsten, 1954, Trend estimators and serial correlation, Cowles Commission discussion paper no. 383 (Chicago, IL).

Rao, R.C., 1990, Compensating heterogeneous salesforces: Some explicit solutions, Marketing Science 9, 319-41.

Roethlisberger, F.J., 1977, The elusive phenomena, edited by G.F.F. Lombard (Harvard University Press, Cambridge, MA).

Schlesinger, L.A. and J.L. Heskett, 1991a, Enfranchisement of service workers, California Management Review, Summer, 83-100.

Schlesinger, L.A. and J.L. Heskett, 1991b, The service-driven service company, Harvard Business Review, Sept.-Oct., 71-81.,

Schwadei, F., 1990a, At Sears, unpopular pay policy reflects fuss in retail industry, Wall Street Journal, Jan. 13, B1.

Schwadei, F., 1990b, Chain finds incentives on hard sell, Wall Street Journal, July 5, Bl.

Simons, R. and H. Weston, 1991, Nordstrom: Dissension in the ranks?, Paper no. 9-191-002 (Harvard Business School, Boston, MA).

Sloan, R., 1993, Accounting earnings and top executive compensation, Journal of Accounting and Economics 16, 55-100.

Stevenson, R.W., 1989, Watch out Macy’s, here comes Nordstrom, New York Times Magazine, Aug. 27, 34-40.

Taylor, F.W., 1911, The principles of scientific management (Norton, New York, NY). 
Thaler, R., 1986, The psychology of choice and the assumptions of economics, in: A.E. Roth, ed., Laboratory experimentation in economics: Six points of view (Cambridge University Press, New York, NY).

Thurik, R. and N. Van der Wijst, 1984, Part-time labor in retailing, Journal of Retailing 60, 6280.

Vroom, V.H., 1965, Work and motivation (Wiley, New York, NY).

Wagner, J.A, P.A. Rubin, and T.J. Callahan, 1988, Incentive payment and nonmanagerial productivity: An interrupted time series analysis of magnitude and trend, Organizational Behavior and Human Decision Processes 42, 47-74.

Weitzman, M.L., 1980, The 'Ratchet Principle' and performance incentives, Bell Journal of Economics, Spring, 302-308.

White, H., 1980, A heteroskedasticity-consistent covariance matrix estimator and a direct test for heteroskedasticity, Econometrica 48, 817- 838.

Wood, R., A. Bandura, and T. Bailey, 1990, Mechanisms governing organizational performance in complex decision-making environments, Organizational Behavior and Human Decision Processes 46, 181-201.

Yin, T., 1992, Sears is accused of billing fraud at auto centers, Wall Street Journal, June 12, B1. WSJ, 1989, Commission selling spreads at department stores, Wall Street Journal, March 21. WWD, 1988, Younkers sets sales incentives. Women's Wear Daily, March 29. WWD, 1991, CHH cutting back on commissions, Women's Wear Daily, Jan. 16, 5. 